\title{
Effects of Ovariectomy and Administration of Sex Hormones on Prolactin Cell Types in Mice
}

\author{
Toshio HARIGAYA \\ Department of Anatomy, Faculty of Medicine, \\ Kyoto University, Sakyo-ku, Kyoto-shi 606 \\ Present address : School of Agriculture, Meiji University, \\ Tama-ku, Kawasaki-shi 214
}

(Received February 15, 1991)

Key words : prolactin, pituitary gland, ovariectomy, estradiol

Light and electron microscopic immunohis. tochemistry of prolactin (PRL) cells in the anterior pituitary gland in mice has been investigated and PRL cells in the pituitary gland of both male and female adult mice were classified into three types mainly based upon sizes and shapes of immunoreactive PRL secretory granules". The type I PRL cell is scarce in the pituitary gland of both sexes. The type II PRL cell is frequently seen in adult male mice. The type III PRL cell is predominant in adult female mice ${ }^{1}$. These sexual dimorphic features of PRL cells became apparent during puberty ${ }^{21}$. SASAKI and SANO ${ }^{6-8)}$ have previously reported that the important role of ovary for sex differences of PRL cells in the anterior pituitary gland, although their investigations were based on the convenient electron microscopic observation. In the present study, an attempt was made to clarify whether sex hormones would influence the phenotypic differentiation of PRL cell types in mice.

\section{Materials and Methods}

Adult male and female mice of the $\mathrm{C} 57 \mathrm{BL}$ strain (13-18 weeks old) were used in the present study. They were maintained at $25 \pm$ $2^{\circ} \mathrm{C}$ with $12 \mathrm{~h}$ light: $12 \mathrm{~h}$ darkness, and food (Oriental Mouse Chow, Tokyo) and water were available ad libitum.

Ovariectomy was performed in female mice under pentobarbital sodium (Nembutal, Abbott) anaesthesia. Immediately thereafter, ovariectomized mice were implanted subcutaneously with a silastic tube $(5 \mathrm{~mm}$ long, o.d. $2 \mathrm{~mm}$, plain style $1 \mathrm{~mm}$, Dow Corning) containing estradiol-17 $\beta$ or testosterone crystal (Sigma), or with an empty silastic tube as controls. Male mice were implanted subcutaneously with a silastic tube containing estradiol$17 \beta$ or with an empty silastic tube as controls.

One week after the treatment, mice were killed by heart puncture and the pituitary glands were removed, and fixed in a picric acid formaldehyde solution ${ }^{9 /}$ for $2 \mathrm{~h}$ at $4^{\circ} \mathrm{C}$. These tissues were postfixed in $1 \%$ osmium tetroxide in $0.1 \mathrm{M}$ phosphate buffer for $1 \mathrm{~h}$ and

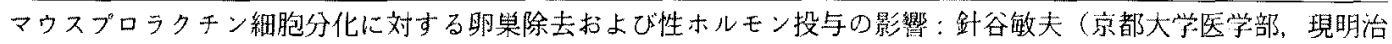
大学農学部，川绮市多摩区 214)

Anim. Sci. Technol. (Jpn.) 62 (8): 711-713 711 


\section{HARIGAYA}

dehydrated through a graded series of ethanol solution and embedded in Epon 812.

The PRL cells in the anterior pituitary gland were identified by electron microscopic indirect immunohistochemical method using anti-mouse PRL rabbit serum provided by Dr. K. Конмото previously described". In all electron micrographs examined, the total numbers of nuclei of PRL cells in each cell type and all the anterior pituitary cells including PRL cells were counted. Any cells revealing only parts of their cytoplasm were not counted. Electron micrographs used for cellular counting were taken from ultrathin sections located in the areas of 10 grids of a $\# 200$ square mesh. For the cell count, four mice were used and the number of each type of PRL cells was pooled in each group.

PRL cells were classified into types I, II and III according to the criteria established for mouse PRL cells previously ${ }^{13}$ : the crieria being based mainly upon sizes and shapes of immunoreactive PRL secretory granules as follows. The type I PRL cell is oval or polygonal in cell shape, and contains spherical PRL secretory granules, about $100 \mathrm{~nm}$ in diameter, and poorly developed endoplasmic reticulum and Golgi apparatus. The type II PRL cell usually shows cup-shaped or triangular cellular configulation and possesses elongated cytoplasmic processes by which it embraces oval-shaped neighboring cells containing non-PRL-immunoreactive secretory granules. The type II PRL cell contains spherical PRL secretory granules, $150-200 \mathrm{~nm}$ in diameter, and moderately developed cytoplasmic organelles. The type III PRL cell is oval or polygonal in its cell shape and contains variably-sized polymorphic secretory granules, $300 \mathrm{~nm}$ in maximal diameter, and well developed cytoplasmic organelles.

\section{Results and Discussion}

Table 1 shows the percentage of total PRL cells among all the anterior pituitary cells and that of each type of PRL cells in the all PRL cells. When ovariectomized female mice were treated with estradiol-17 $\beta$, total number of PRL cells in the anterior pituitary gland increased slightly compared with that of the ovariectomized control mice. The ratio of the number of type III PRL cells to the total number of all PRL cells increased, while the ratio of either type I or II PRL cells to the total decreased. Then, type III PRL cells became predominant in mice with estradiolimplants. On the other hand, in testosterone treated mice, the ratio of either type I, II, or III PRL cells to the total number of all PRL cells did not change compared with that in the control, although the percentage of total PRL cells in all the pituitary cells decreased.

In male mice, estradiol-implants also increased the proportion of type III PRL cells and decreased that of type I and II PRL cells. Although the pcrcentage of total PRL cells among all the anterior pituitary cells is slightly increased by the estradiol treatment in

Table 1. Effects of estradiol or testosterone in ovariectomized mice and of estradiol in male mice on the ratio of PRL cells in the total number of anterior pituitary gland cells and the relative proportions of three types of PRI, cells.

\begin{tabular}{lllccl}
\hline \hline Experiment & & PRL cell & type I & type II & type III \\
\hline \multirow{2}{*}{ female } & ovx control $\left(269^{\mathrm{a}}\right)$ & $45.3 \%$ & $3.3 \%$ & $41.5 \%$ & $55.2 \%$ \\
& ovx $+\mathrm{E}_{2}(261)$ & 54.8 & 1.4 & 3.5 & 95.1 \\
\multirow{3}{*}{ male } & ovx $\mathrm{T}(397)$ & 36.9 & 5.1 & 47.1 & 47.7 \\
& control $(358)$ & 24.0 & 12.8 & 44.8 & 42.4 \\
& $\mathrm{E}_{2}(247)$ & 29.2 & 2.5 & 10.4 & 87.1 \\
\hline
\end{tabular}

ovx, ovariectomy; $E_{2}$, estradiol-17 $\beta ; \mathrm{T}$, testosterone. a total number of counted pituitary cells. 
male mice, but it is still lower than that of female mice.

In the present experiments, the implantation of estradiol-17 $\beta$ crystal in adult ovariectomized female mice and non-orchidectomized male mice yielded the increase of type III PRL cells at the expense of types I and II PRL cells. On the other hand, the implantation of testosterone in adult ovariectomized female mice caused no change in the ratio of the number of either type I, II or III PRL cells to total number of PRL cells. In the previous study $^{3}$, neonatal administration of estrogen in male mice had no effect on the proportion of three types of PRL cells when they were killed after puberty. The existence of ovary during puberty seems to be essential for the induction of sex differences in PRL cells in mice.

SASAKI and SANO ${ }^{6-8)}$ have previously reported sex differences in the morphology of PRL cells in mice and indicated that the presence of ovary after puberty is essential for the female phenotypic differentiation of the anterior pituitary gland. The present study indicates that estrogen is related to the sex-linked phenotypic differentiation of PRL cells, particularly to the appearance of type III PRL cells. The type III PRL cell in female mice was previously found to increase in number during puberty, followed by sex-linked differences in types of PRL cells in mature mice ${ }^{2}$. The type III PRL cell also increased in grafted pituitary glands in mice and this increase was prevented by the administration of bromocriptine ${ }^{4)}$. These data suggest that the differentiation into type III represents the attainment of the high secreted activity of PRL cells. The increase in the number of type III PRL cells in the anterior pituitary gland during puberty seems to correspond to the increase of the serum level of PRL towards puberty in mice ${ }^{51}$.

\section{Acknowledgements}

The author is indebted to Dr. K. Конмото, University of Tokyo, for providing the anti- mouse prolactin serum.

\section{References}

1) Hartgaya, T., K. Конmoto and K. Hoshino, Immunohistochemical identification of prolactin-producing cells in the mouse adenohypophysis. Acta Histochem. Cytochem., 16:51-58. 1983.

2) Harigaya, $T$. and $K$. Hoshino, Immunohistochemical study of postnatal development of prolactin-producing cells in $\mathrm{C} 57$ BL mice. Acta Histochem. Cytochem., 18 : 343-351. 1985.

3) Harigaya, T,, $H$. Hashimoto and $K$. Hoshino, Effects of estrogen on prolactin cells in male mice. in Pars Distalis of the Pituitary Gland-Structure, Function and Regulation (Yoshimura, F, and A. GorbMAN, eds) 147-149. Elsevier Science Publishers B.V. Amsterdam. 1986.

4) Harigaya, T. and K. Hoshino, Immunohistochemical identification of prolactinproducing cells in pituitary isografts in CBA mice. Anatomisher Anzeiger, 167 : 205-212. 1988.

5) Michael, S.D., S.B. Kaplan and B.T. Macmillan, Peripheral plasma concentrations of LH. FSH, prolactin and GH from birth to puberty in male and female mice. J. Reprod. Fert., 59 : 217-222. 1980.

6) SASAKI, F. and M. SANO, Role of the ovary in the sexual differentiation of prolactin and growth hormone cells in the mouse adenohypophysis during postnatal development: a stereological morphometric study by electron microscopy. J. Endocr., 85: 283-289. 1980.

7) SASAKI, F. and M. Sano, Role of the ovary in the sexual differentiation of prolactin and growth hormone cells in the mouse adenohypophysis: a stereological morphometric study by electron microscopy. J. Endocr., 93: 117-121. 1982.

8) SASAKI, F. and M. Sano, Role of the ovary in sexual differentiation of lactotrophs and somatotrophs in the mouse adenohypophysis: a stereological morphometric study by electron microscopy. J. Endocr., 99 : 355-360. 1983.

9) Stefanini, M., C. Demartino and L. ZAMBONI, Fixation of ejaculated spermatozoa for electron microscopy. Nature, 216 : 173-174. 1967. 